\title{
Migração : Reflexos de um Espelho
}

Migration : Reflections from a Looking Glass

\section{William Watson*}

*Arquiteto e escritor sediado em Nova lorque. É co-fundador do escritório Castro Watson Architects e professor convidado da Pratt Institute and Parsons School of Design. Recebeu seu diploma como mestre na University of Texas em Austin e seu BA em Economia na Princeton University.wawatson99@gmail.com

\section{Palavras-chave:}

Migrantes.

Utopia.

Heterotopia.

\section{Keywords:}

Migrants.

Migrants.

Heterotopia.

\section{Resumo}

A dissertação de mestrado de Rodrigo Lefèvre, Projeto de acampamento de obras: uma utopia, oferece um modelo de produção de moradias para migrantes na periferia de São Paulo com base em colaborações enriquecedoras entre migrantes que constroem suas moradias e a assessoria técnica. Esta parceria, uma evolução das teorias anteriores sobre a eliminação de relações hierárquicas entre arquitetos e operários, lembra os princípios fundamentais que sustentam as colaborações anteriores de Lefèvre com Sérgio Ferro e Flávio Império no Grupo Arquitetura Nova. Em sua proposta de acampamento, essas interações tornam-se um mecanismo para equilibrar a transmissão cultural da herança deslegitimadora dos migrantes na perspectiva de um equilíbrio e de uma diversidade demográfica. Embora sugerida como uma utopia, essa proposta também pode ser entendida como uma heterotopia - um paradigma alternativo, mas plausível, para a construção de moradias para migrantes. Como uma heterotopia, a proposta de Lefèvre, assim como de outros textos publicados pelos membros da Arquitetura Nova, é ao mesmo tempo uma crítica às condições vigentes e uma aspiração de solução. E, como crítica e expectativa, o projeto de Lefèvre ilustra as importantes contribuições feitas pelos migrantes no desenvolvimento da sociedade e nos convida a avaliar e redescobrir nossa empatia por

\section{Abstract}

Rodrigo Lefèvre's Master's dissertation, Projeto de um Acampamento de Obra: Uma Utopia, offers a production model for migrant housing along the periphery of São Paulo based upon mutually enriching collaborations between migrants constructing their dwellings and mentoring technicians. This partnership, an evolution of previous theories on eliminating hierarchical relationships between architects and laborers at building sites, recalls the foundational principles underpinning Lefèvre's earlier collaborations with Sérgio Ferro and Flávio Império under the collective Arquitetura Nova. In his proposed work encampment, these interactions become a mechanism to rebalance cultural transmission away from delegitimizing migrant heritage and towards an equitable and heterogenous urban demography. Though suggested as a utopia, this framework also may be understood as a heterotopia-an alternate yet plausibly concurrent paradigm for the construction of migrant housing As a heterotopia, Lefèvre's proposal, similar to other texts published by the members of Arquitetura Nova, is simultaneously a critique of prevailing conditions as well as an aspirational solution. And, as both criticism and expectation, Lefèvre's project illustrates the important contributions made by migrants in the development of society and invites us to evaluate and rediscover our empathy towards them. eles. 


\section{Migração: Reflexos de um Espelho}

Após uma carreira já significativa como professor e arquiteto, Rodrigo Lefèvre retornou à FAU-USP aos 38 anos para cursar uma pós-graduação em Estruturas Ambientais Urbanas. Durante este intervalo acadêmico, Lefèvre usou sua dissertação de mestrado como reflexão sobre as influências e teorias que sustentam seu trabalho. O texto resultante, intitulado Projeto de Acampamento: Uma Utopia, investiga a situação dos migrantes no Brasil e propõe enfrentar seu infortúnio com um sistema de casas autoconstruídas suportado por um acampamento de escolas de construção. É uma composição incomum de indivíduo [migrantes], tempo [transição] e localização [utopia] que sintetiza a simultaneidade em camadas que havia sido um diferencial do trabalho anterior de Lefèvre com Sérgio Ferro e Flávio Império sob o coletivo Arquitetura Nova.

A escolha dos migrantes como tema por Lefèvre não é de surpreender. Desde suas experiências iniciais de trabalho com Sérgio Ferro em dois edifícios residenciais de Brasília, Lefèvre ficava chocado com as condições de vida e de trabalho enfrentadas pelos migrantes que estavam construindo a nova capital do Brasil. Esses trabalhadores, desesperados por um emprego, estavam sujeitos à falta de moradia e a um risco excessivo enquanto trabalhavam arduamente nos grandes e complicados edifícios de concreto que delineavam a nova capital. Sem o fornecimento de acomodações adequadas pelo governo, esses migrantes rapidamente aderiram à tradição de moradias autoconstruída. "Para muitos membros das camadas mais baixas da população de Brasília, a ocupação era simplesmente a única possibilidade", observa David Epstein, "pois eles não foram abençoados com influência política...e não tinham dinheiro para resolver seu problema no minúsculo mercado imobiliário privado" (EPSTEIN, David, 1976, p. 112).

Vendo os migrantes como protagonistas da mudança social, Lefèvre e o grupo Arquitetura Nova separaram-se de maneira notável das metodologias de uma geração anterior de arquitetos brasileiros. Esse grupo mais antigo, influenciado por seu envolvimento com o $\mathrm{PCB}$, havia proposto uma forma hierárquica e sequencial de desenvolvimento, na qual a classe média iniciaria uma mudança política que, posteriormente, promoveria melhorias sociais para as classes mais baixas. $O$ coletivo Arquitetura Nova, parte de uma geração mais jovem de comunistas mais radicais, esperava afastar-se desse 'etapismo' defendendo estratégias que enfrentas- sem simultaneamente as inadequações do sistema político e as desigualdades sofridas pelos trabalhadores. Essa rejeição da teorização linear em favor de métodos não hierárquicos e multidirecionais tornou-se um princípio fundamental das teorias, escritos e projetos do coletivo Arquitetura Nova.

Fazendo referência aos trabalhos das antropólogas Eunice Durham e Cláudia Menezes, além do folclorista Marcel Jules Thiéblot, Lefèvre defendeu os migrantes como agentes utópicos porque são motivados pela busca por algo melhor. Para apoiar essa hipótese, ele pega emprestado uma estrutura desenvolvida por Durham, que categoriza tais motivações em dois tipos - subjetivas e concretas. Motivações subjetivas são os desejos pessoais de ter melhores condições de vida que incentivam indivíduos a tomarem decisões locais específicas de deslocamento em busca de uma vida melhor. Referindo-se a Menezes, Lefèvre propõe que "mudança significa, para o migrante, uma busca de melhoria, no seu sentido mais amplo: melhores condições de trabalho, moradia, transporte, conforto, distração, acesso a bens de consumo, educação, saúde. Tudo isso é o que necessariamente se encontra em outro lugar, não aquele em que está" (LEFÈVRE, Rodrigo, 1981, p. 141). Em contraste, motivações concretas são as maiores forças socioeconômicas que regulam o deslocamento dentro de um processo sistemático de mudança e equilíbrio. Referindo-se a Durham, Lefèvre introduz que "a migração foi explicada...como resposta a problemas criados pela estrutura da sociedade nacional e que são fundamentalmente econômicos. ...a migração, que aparece como solução para problemas que afetam a família...é um processo condicionado pelo tipo de organização social da sociedade rural." (LEFĖVRE, Rodrigo, 1981, p. 151). Por meio da migração, a estrutura familiar muitas vezes se vê fragmentada, de tal forma que, "a migração de uma pessoa não é um fato isolado, mas um aspecto de um processo que envolve a movimentação sucessiva de pessoas diferentes e pode-se estender por tempo considerável" (LEFÈVRE, Rodrigo, 1981, pág. 151). Com efeito, as motivações subjetivas são guiadas e impulsionadas pelas motivações concretas.

Ao fazer uma distinção entre essas motivações subjetivas e concretas, Lefèvre aborda a simultaneidade da agência dos migrantes, bem como as forças que impulsionam a mudança e o progresso. Desse modo, as relações subjetivas e as relações concretas tornam-se simbióticas. Pedro Arantes explica que "o migrante 
é o sujeito em transição, que contêm as contradições e as possibilidades de superação histórica brasileira e, ao mesmo tempo, é o avesso do nosso 'milagre' de país moderno". (ARANTES, Pedro Fiori, 2002, p. 134). O migrante é tanto o veículo do desenvolvimento quanto sua consequência.

Para reconhecer a relação entre os migrantes e seu contexto, Lefèvre insere um segundo protagonista em seu modelo de produção - o técnico de nível superior. A polaridade entre os migrantes e esses técnicos visa fomentar a troca de informações. Exteriormente, os técnicos cumprem o papel tradicional de conselheiros dos migrantes sobre práticas de construção adequadas. Os técnicos são necessários porque, "a casa autoconstruída pela sua condição de produzida sem um conhecimento técnico apropriado, pode ser um objeto que atenda mal às necessidades físicas mínimas para a conservação e reprodução da força de trabalho." (LEFÈVRE, Rodrigo, 1981, p. 32). No entanto, a virtude da proposta de Lefèvre reside na reciprocidade que ele imagina para seus protagonistas; o migrante deve ter um impacto igualmente importante sobre o técnico. Com base nas pedagogias de Paulo Freire, Lefèvre explica que, "aquela participação de técnicos de grau superior no modelo de uma produção tem algumas finalidades: a primeira é colocar em discussão dentro do modelo os elementos da cultura burguesa em confronto com os elementos da cultura do povo trazidos pelos migrantes" (LEFÈVRE, Rodrigo, 1981, p. 65). "a reformulação dos técnicos de grau superior em busca de um conhecimento, de uma ciência, de uma tecnologia mais correta da construção da nova sociedade." (LEFÈVRE, Rodrigo, 1981, p. 65).

Localizando a transferência de ideias em um canteiro de obras revisita as teorias desenvolvidas anteriormente pelo coletivo Arquitetura Nova sobre o arquiteto e o operário. Contrariando a concepção do arquiteto como figura controladora, uma metodologia de trabalho privilegiada por arquitetos modernistas, o coletivo Arquitetura Nova imaginou um processo de projeto e construção no qual a inspiração e a responsabilidade se mesclassem a todos os participantes do local. Com efeito, as responsabilidades do arquiteto deveriam ser desmistificadas e ter permissão de migrar para os operários. Essa mudança transformaria um local de trabalho 'hierárquico' em um local 'colaborativo'. Em vez de imaginar a construção como sequencial - projeto seguido de execução - a inspiração seria gerada de ambos os lados do projeto. As sugestões do arquiteto e do operário para o projeto de construção aconteceria simultânea e simbioticamente.

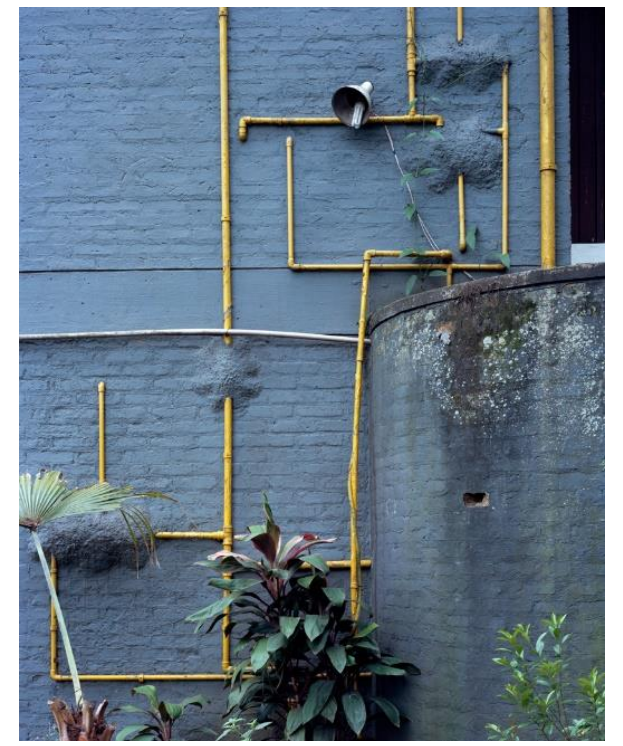

Figura 1. Casa Dino Zammataro, Rodrigo Lefèvre, São Paulo, 1970. Fonte: TATEWAKI NIO, 2019.

Do ponto de vista arquitetônico, um resultado notável dessa migração de ideias foi a exposição disciplinada e deliberada do trabalho pelos 'ofícios'. Encanamentos, dutos de ventilação e fiação elétrica foram expostos para promover a valorização da infraestrutura do projeto e seus instaladores. Por exemplo, encanamentos foram abertamente exibidos em muitos dos projetos residenciais experimentais de Lefèvre - incluindo aqueles que animam a fachada da Casa Dino Zammataro (Figura 1) e o interior da Casa Perry Campos (Figura 2).

Essa técnica não apenas levou a uma maior eficiência no canteiro de obras, mas também a uma migração arquitetônica: sistemas originalmente ocultos por hierarquias de construção obsoletas são capazes de retornar a um local de observação e apreciação. O projeto arquitetônico e os sistemas de engenharia necessários são vistos e compreendidos simultaneamente. 


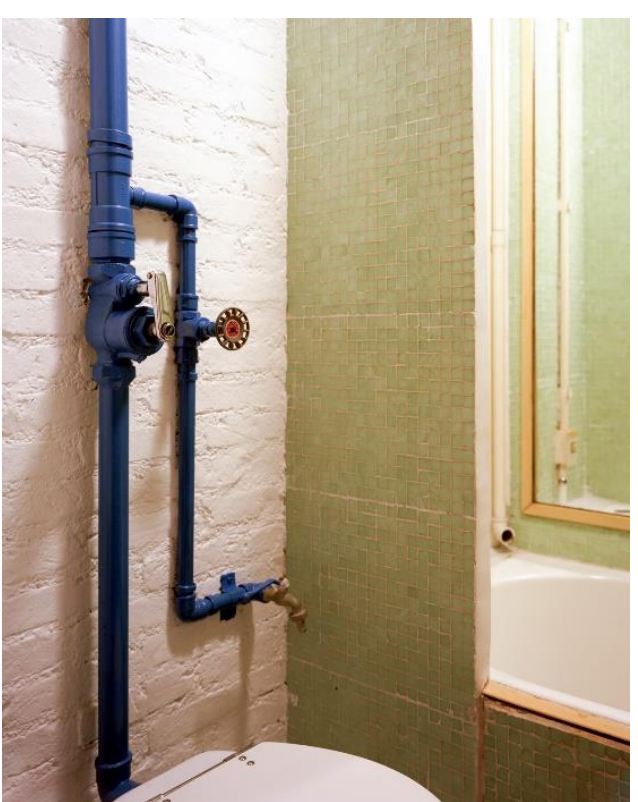

Figura 2. Casa Pery Campos, Rodrigo Lefèvre e Nestor Goulart Reis Filho, São Paulo, 1970. Fonte: TATEWAKI NIO, 2019.

Em sua dissertação, Lefèvre apresenta seu modelo de produção com base em um digrama de blocos (Figura 3). O lado esquerdo do diagrama apresenta seus protagonistas - o migrante e o técnico de nível superior. Os migrantes chegam à Região Metropolitana de São Paulo (RMSP) vindos de outras regiões do Brasil e os técnicos podem entrar no modelo de produção de fontes locais e não locais. Esses participantes, por meio de uma troca de cultura, educação e trabalho, irão colaborar na periferia da cidade para produzir um acampamento de infraestrutura comum e casas autoconstruídas. Essa colaboração é mostrada na parte superior do diagrama de blocos, onde imagina-se a produção como um processo de discussão, projeto e construção. Isso proporciona alojamento aos migrantes e novas experiências e influências ao técnico de nível superior. Após as transformações dos participantes, estes, juntamente com sua cultura e infraestrutura recémdesenvolvidas, ficam disponíveis para ingressar na força de trabalho da produção em geral. O resultado da integração dos protagonistas na infraestrutura metropolitana é imaginado no lado direito do esquema.

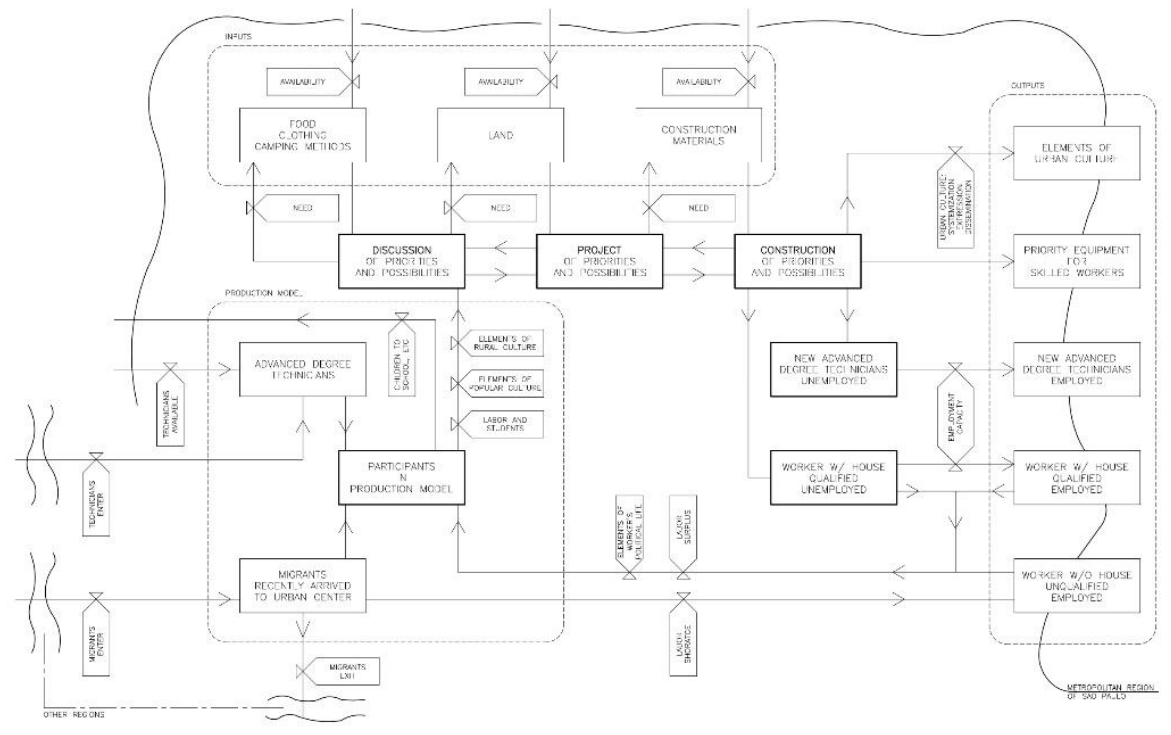

Figura 3. Esquema de Blocos Ilustração do Modelo de Uma Produção, Na Época de Transição, Projeto de Um Acampamento de Obra: Uma Utopia, Rodrigo Lefèvre, Dissertação de Mestrado, 1981, p. 57. Fonte: Redesenhado pelo Autor.

O diagrama de Lefèvre é uma reminiscência dos encanamentos expostos que distinguem seus projetos residenciais - o fluxo do processo imaginado como eletrodutos que circulam por meio de um sistema controlado por válvulas que representam causas e influências. Ele explica que, "nessas setas existirão elementos que são representações do prendar ou do soltar o fluxo entre situações ou elementos para que ele aconteça em maior ou menor quantidade e em mais ou menos tempo." (LEFÈVRE, 1981, p. 58). Algumas dessas válvulas têm títulos elementares como 'capacidade de emprego da sociedade', enquanto outras oferecem descrições mais enfáticas, como 'elementos da vida política do trabalhador' ou 'sistematização, expressão, e divulgação da cultura urbana do povo'. A igual atenção dada aos 'blocos' e às 'válvulas' agrega importância tanto aos elementos servidos como aos servidores no modelo de produção e corresponde à proposta de igualdade dos migrantes e técnicos. 


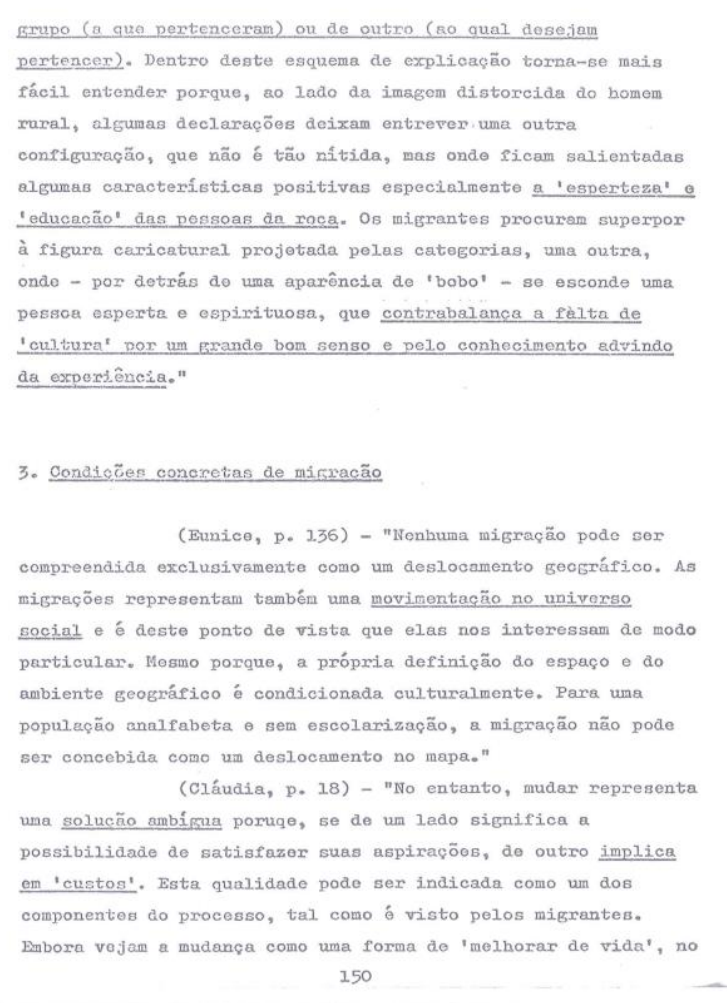

Figura 4. Projeto de Um Acampamento de Obra: Uma Utopia, Rodrigo Lefèvre, Dissertação de Mestrado, 1981, p. 150. Fonte: Acervo da FAU-USP.

As analogias com a construção civil são ainda mais evidentes nos métodos de avaliação que Lefèvre aplica ao seu modelo de produção, tomando emprestado os termos 'corte transversal' e 'corte longitudinal' dos desenhos arquitetônicos. Lefèvre define o corte transversal como, "o conjunto de relações existentes em um momento dado do desenvolvimento do trabalho, relações entre coisas e fenômenos" (LEFÈVRE, Rodrigo, 1981, p. 70). Em contrapartida, ele define o corte longitudinal como "Todo esse conjunto de relações e elementos em transformação no tempo, por causas naturais e / ou pela intervenção humana" (LEFÈVRE, Rodrigo, 1981, p. 72). Usando esses dois métodos seccionais, Lefèvre sugere que seu modelo de produção deve ser imaginado de várias maneiras, em várias escalas e em vários momentos do tempo. Tal ponto de vista torna o significado multifacetado e simultâneo de cada componente mais discernível. Lefèvre explica, "cada elemento pode ser visto por três aspectos: como produto de um processo...como meio de produção...e como elemento que desencadeia um outro" (LEFÈVRE, Rodrigo, 1981, p. 73). Cada elemento não tem apenas uma função específica a desempenhar, em um momento específico, mas também um impacto gerador no modelo de produção ao longo do tempo. Esta forma de avaliação destaca o papel essencial dos migrantes na evolução operacional do sistema.

A inclinação de Lefèvre a relações não hierárquicas e multifacetadas, seja em métodos estratificados de explicação ou de análise, é uma cognição profundamente enraizada em seu trabalho anterior com o coletivo Arquitetura Nova. É fundamental para seu método de trabalho e manifesta-se em todos os níveis, inclusive no formato de sua escrita. Ao longo da dissertação, Lefèvre apresenta suas fontes de pesquisa por meio de uma costura incomum de citações, alternando entre autores e, com frequência, apresentando suas descobertas fora da sequência do material de referência. Sobre essa colcha de retalhos de citações, Lefèvre oferece uma narrativa extra ao enfatizar frases importantes dentro das citações de maneira seletiva (Figura 4). Ele descreve esta técnica como "um mosaico, uma colagem formada de trechos...com frases ou palavras sublinhadas por mim, na medida que eles se complementam, se confirmam, e às vezes, se negam" (LEFÈVRE, Rodrigo, 1981, p. 124). Essa técnica, presciente de hipertextos, estabelece uma relação tridimensional entre as citações e os argumentos de Lefèvre que imbui sua escrita com empatia e a complexidade que se manifestam na obra anterior do coletivo

Arquitetura Nova. Ele também demonstra a forma como a metodologia e o processo são vitais para o desenvolvimento e evolução de ideias inovadoras.

O modelo de produção de Lefèvre é uma aceitação dos assentamentos de migrantes na periferia de São Paulo e também uma proposta de os melhorar. Ao defender essas formas de assentamento, Lefèvre dá continuidade a um argumento prolongado sobre a virtude da autoconstrução de moradia. Sua proposta contrasta com teorias "dualistas" que acreditam que os trabalhadores migrantes são muito arcaicos e, portanto, em oposição à industrialização do Brasil, bem como com os teóricos marxistas que argumentam que as casas autoconstruídas irão 
reduzir o salário prevalecente para a classe trabalhadora. O capital excedente que os migrantes ganharam por construir as próprias casas reduzirá suas necessidades financeiras, o que permitirá, subsequentemente, reduzir os salários vigentes. Efetivamente, todas as economias obtidas pelos migrantes serão transferidas para seus empregadores. Lefèvre reconhece e ameniza essas críticas ao localizar seu modelo de produção em uma 'época de transição', no qual o 'Estado' passa a controlar os 'meios de produção'. Lefèvre explica que, "só lá, na época de transição, onde algumas relações econômicas e políticas estiverem alteradas é que posso aceitar participar de um processo de autoconstrução em larga escala." (LEFÈVRE, Rodrigo, 1981, p. 31). Nesse novo sistema econômico, no qual as forças impulsionadas pelo mercado são substituídas por uma estrutura mais socialista, a desvalorização do trabalho causada pelas casas autoconstruídas seria evitada. A decisão de Lefèvre de localizar seu modelo de produção durante uma 'época de transição' também pode ter a intenção de sugerir uma qualidade utópica em uma proposta que, de outra forma, é notável por sua viabilidade. Miguel Buzzar explica que, "todas as referências...estão ao alcance de uma efetivação imediata. .... a autoconstrução autogerida não era uma utopia. ...e o modelo 'dito' utópico, apesar de reportar a outro momento, mantém uma relação operativa com o presente..." (BUZZAR, Miguel Antonio, 2019, p. 255).

Outra possibilidade é que o modelo de produção de Lefèvre seja menos uma utopia tradicional, orientada a um destino aspiracional e potencialmente inatingível, e mais a provocação de uma realidade oposta, mas concorrente. Ou seja, Lefèvre não apresenta um substituto para o modelo atual, mas uma alternativa síncrona na esperança de estabelecer um diálogo. Nesse sentido, o acampamento de Lefèvre é mais equivalente a uma heterotopia introduzida por Michel Foucault. Esses tipos de 'outros' espaços podem ser classificados, segundo Foucault, em duas categorias principais - locais de crise e locais de desvio, nos quais ambos os grupos passam por algum tipo de separação da sociedade. A dissertação de Lefèvre oferece evidências substanciais sobre o deslocamento de migrantes e analisa de que forma as alterações nas estruturas sociais causadas por seus deslocamentos constituem uma crise para os migrantes e suas famílias. Além disso, a provável remoção dos migrantes para a periferia da cidade é um mecanismo tanto de desvio quanto de crise. Arantes explica que, "ao definir o migrante como sujeito, o Estado como provedor e a periferia como local planejamento, Rodrigo está percebendo que o processo vertiginoso de urbanização precisa ser enfrentado rapidamente, antes que a escola do problema comece a invalidar qualquer solução", (ARANTES, Pedro Fiori, 2002, p. 134).

Foucault postula que as heterotopias oferecem funções precisas e determinadas, que são sintomáticas da sociedade em que existem. Em resposta à crítica de que os assentamentos de migrantes nos limites da cidade representam uma falha de assimilação à sociedade urbana moderna, Epstein explica que este ponto de vista é "amplamente incorreto e enganoso...os ocupantes sem-teto são economicamente privados, mas, longe de serem marginais, [são] centrais na construção da nova capital. ...As ocupações não são um resquício da vida rural brasileira, mas sim um...modo fundamental de expansão urbana" (EPSTEIN, David, 1973, p. 15). A proposta de Lefèvre de tratar positivamente e facilitar esses acampamentos, em vez de apagá-los ou amenizá-los, é um reconhecimento de sua função heterotópica.

Outro princípio das heterotopias é que elas sobrepõem espaços diferentes, às vezes incompatíveis, em um só local. Essa sobreposição é fundamental para o modelo de produção de Lefèvre, no qual a dessemelhança das ideias de criação de espaço e construção trazidas por migrantes e técnicos cria um diálogo que motiva suas respectivas transformações. Os próprios migrantes também são locais de sobreposição, pois mesclam suas tradições rurais com a cultura urbana de seu lar recém-adotado. Lefèvre cita Menezes quando escreve que os migrantes "demonstram que estão buscando identificar-se com o modelo que formularem do homem urbano, sendo a motivação básica para isto o fato de estarem morando na cidade. Esta identificação implica necessariamente na negação da realidade anterior...". (Lefèvre, Rodrigo, 1981, p. 149).

Foucault também sugere que as heterotopias estão "ligadas a fatias no tempo...em uma espécie de ruptura absoluta com seu tempo tradicional" (FOUCAULT, Michel e MISKOWIEC, Jay, 1986, p. 26). Essas rupturas heterocrônicas podem ser definidas como transitórias (como festivais e aldeamentos turísticos) ou acumulatórias (como museus e bibliotecas). Acampamentos de migrantes ao longo dos limites da cidade oferecem uma qualidade transitória, que é resultado direto da necessidade de conveniência e flexibilidade nas acomodações dos migrantes. Epstein explica que, "o imigrante brasiliense, chegando com pouco capital, 
pode construir uma barraca muito pequena e primitiva em poucas horas ou dias, e imediatamente partir para o seu trabalho principal, ganhando dinheiro de uma forma ou de outra" (EPSTEIN, David, 1976, p. 111). Também é importante observar que Lefèvre sugere abertamente uma ruptura com a época tradicional ao localizar seu modelo de produção em uma 'época de transição'.

As relações heterocrônicas são fundamentais para o entendimento das teorias do coletivo Arquitetura Nova. Ao contrário das teses dualistas, em que os aspectos primitivos do Brasil são considerados em oposição direta à sua modernização, Arquitetura Nova defendia que o desenvolvimento industrial do país deve ser aceito simultaneamente com as características primitivas e históricas que o sustentam. As teses dualistas defendiam a "a industrialização contra o atraso "feudal"', explica Ana Koury, "a industrialização contra o atraso "feudal"...para as quais a herança rural correspondia a um modo de produção feudal que seria superado pela modernização industrial burguesa." (KOURY, Ana Paula, 2019, p. 24 ) Em contrapartida, Arquitetura Nova preconizava pedagogias que previam "uma aproximação com os problemas urbanos do subdesenvolvimento, propondo um engajamento com a realidade histórica na qual atuavam os arquitetos" (KOURY, Ana Paula, 2019, p. 26). Ao defender tanto os aspectos transitórios da sociedade, focando nas populações migrantes, quanto os acumulatórios da sociedade, no favorecimento da história e das técnicas tradicionais de construção, Arquitetura Nova e Lefèvre imaginaram o progresso mais como um modelo heterocrônico do que binário.

A característica mais potente das heterotopias é que elas "têm uma função em relação a todo o espaço que resta" (Foucault, Michel e MISKOWIEC, Jay, 1986, p. 27). Ou seja, por serem reais e ilusórias, eles se tornam um espelho dois espaços unidos pela visão durante uma reflexão instantânea. Foucault escreve: "o espelho é como uma heterotopia nesse sentido: ele torna este lugar que ocupo no momento em que me olho no vidro ao mesmo tempo absolutamente real, conectado com todo o espaço à sua volta, e absolutamente irreal" (FOUCAULT Michel e MISKOWIEC, Jay, 1986, p. 24). A proposta de Lefèvre pode ser vista tanto como solução quanto como crítica. A heterotopia é inversionária, de modo que a relação entre os 'outros espaços' e os 'espaços que permanecem' abre espaço para a migração de ideias.
É apropriado que os próprios integrantes do coletivo Arquitetura Nova acabem se tornando migrantes - Sérgio Ferro emigrou para a França, após as dificuldades políticas geradas pelo governo militar após o golpe de 1964, e Rodrigo Lefèvre partiu para Guiné-Bissau logo após terminar sua dissertação. Enquanto estava na África Ocidental, trabalhando em um sistema de saúde que projetou quando trabalhava para a Hidroservice, Lefèvre morreu em um acidente automobilístico aos 46 anos. Décadas depois, conforme a valorização de Rodrigo Lefèvre e do coletivo Arquitetura Nova se desenvolve fora do Brasil, uma nova migração está ocorrendo. Suas teorias reconhecem o papel fundamental dos migrantes na construção da sociedade e dão exemplos essenciais de empatia em todas as suas formas. Além disso, a utopia proposta por Lefèvre é um espelho que reflete nossa subjetividade de volta para nós mesmos, permitindo-nos redescobrir nossa humanidade. Uma discussão sobre a utopia e a contribuição significativa que os migrantes podem dar em sua criação nos oferece o potencial para uma nova época de transição.

\section{Referências}

ARANTES, Pedro Fiori. Arquitetura Nova: Sérgio Ferro, Flávio Império e Rodrigo Lefèvre, de Artigas aos mutirões. São Paulo: Editora 34, 2002.

BUZZAR, Miguel Antonio. Rodrigo Brotero Lefèvre e a vanguarda da arquitetura no Brasil. São Paulo: Edição Sesc São Paulo, 2019.

EPSTEIN, David G.. Brasilia: Plan and Reality. A Study of Planned and Spontaneous Urban Development. Los Angeles: University of California Press, 1973.

FOUCAULT, Michel. Of Other Spaces. Jay Miskowiec (trans.). Diacritics, Baltimore, ano 16, n. 1, p. 22-27, Spring 1986.

KOURY, Ana Paula. Arquitetura Moderna Brasileira. Uma crise em desenvolvimento. Textos de Rodrigo Lefèvre (1963-1981). Ana Paula Koury (org.) - São Paulo: Editora da Universidade de São Paulo, FAPESP. 2019.

LEFÈVRE, Rodrigo Brotero. Projeto de um Acampamento de Obra: Uma Utopia. Dissertação (Mestrado em Estruturas Ambientais Urbanas) - Faculdade de Arquitetura e Urbanismo, Universidade de São Paulo, São Paulo, 1981. 